Aletria, Belo Horizonte, v. 29, n. 3, p. 9-18, 2019

\title{
Mapeamentos da teoria da literatura na contemporaneidade
}

Escrever e pensar teoricamente em tempos de incerteza é quase como tatear. A busca por modos de se enunciar e interpelar a cena teórica e social atual parece presa a um paradoxo em que urgência e paralisia se amalgamam sem que, por isso, seja mais fácil criar um contorno, conferir uma definição, atribuir uma forma às práticas de investigação e pesquisa que se inserem na área da Teoria da Literatura. Parece mesmo impossível configurar uma moldura capaz de conter um todo disforme e rebelde, que se lança por fronteiras disciplinares, atento a preocupações díspares, negociando com referências e interesses antitéticos e muitas vezes antagônicos.

Todavia, se paramos para observar essa informe forma, como quem observa gotas d'agua a cair em um lago, percebemos que há um movimento em comum que rege essas escritas: o olhar retrospectivo. Olhar que atinge a Teoria por um certo viés e sobre ela projeta diferentes tipos de inquietações, seja em relação ao limite e estatuto do objeto literário, seja em relação aos procedimentos críticos e a constituição do leitor e da leitura, às questões estético-formais, seja em relação aos conceitos e posições que, dispostos de forma reflexiva, devem colocar à disposição a possibilidade de autocrítica para a própria Teoria. Cada gota d'agua cria ao redor de si um epicentro, mas as ondulações provocadas e provocativas, se deixam tocar umas nas outras. As perspectivas apresentadas são, portanto, distintas, mas não estão fechadas ao diálogo umas com as outras. Se continuamos a pensar sobre seus desdobramentos é como se elas nascessem direcionadas a se expandir tanto de modo a se encontrar com as demais, para finalmente se perderem. Esse encontro se constitui a um só tempo como ponto de inflexão e dinâmica e se define a partir da solicitação ao mapeamento como forma de identificação de problemáticas 
a serem revisitadas e questionadas. Mas esse movimento-em-passado da teoria não se faz em busca de um maior conhecimento desse passado. Não se trata de uma demanda historiográfica a ser cumprida. Tal como o mapa deve ser preciso para ajudar ao viajante futuro, a construção do passado envolvida no mapeamento teórico se direciona ao porvir. E é nesse sentido que, em cada visada que busca determinar certos caminhos como cruciais para uma história da Teoria, podemos reconhecer também um índice do que é fazer teoria hoje: o que buscamos e, portanto, para onde vamos.

A cartografia esboçada nesse dossiê apresenta alguns dos possíveis caminhos. "A teoria da literatura e as desumanidades" toma como mote o sintagma com o qual Ortega y Gasset assina o ensaio "A desumanização da arte" (1924), a fim de empreender um panorama histórico de constituição da disciplina Teoria da literatura, inserindo-a na trama dos debates modernistas que, em movimentos emparelhados, criticam o humanismo e consagram a linguagem, e não mais a capacidade de representação da realidade, como o critério de aferição da obra de arte. Para tanto, Marcus Vinicius de Freitas mobiliza um elenco de pensadores liberais, entre os quais Roger Scruton, Luc-Ferry e Alain Renaut que, afinados na oposição aos "filósofos de 68", são igualmente concordes na caracterização do modernismo (e do pósmodernismo) como crítica à modernidade. O modernismo seria crítico à cultura moderna, sustentada, conforme equação de Daniel Bell, outro pensador convocado pelo crítico mineiro, na conjunção "capitalismo, democracia liberal e autorrealização do individuo", tutelada, por sua vez, pela racionalidade científica. A argumentação remonta àqueles que seriam matrizes do anti-humanismo, a saber, Freud, Marx e Nietzsche, e, noutro fio, não dissociado do anterior, aponta o antirrealismo e a negatividade da arte moderna como fundamentos dos "pensadores da diferença" e da própria teoria literária, que passa a se fixar "antes na linguagem que diz do que no que diz a linguagem". Neste quadro, enquanto os modernistas anti-humanistas se valeriam, "contrários ao cálculo e ao racionalismo", da opacidade da arte moderna como "um modo oblíquo de interpelação da vida, os modernos defenderiam, a partir de parâmetros de sistematização, observação, experimento e raciocínio, a busca dos universais humanos expressos pela linguagem. $\mathrm{O}$ percurso teórico realizado demonstra com clareza as linhas de força concernentes ao embate filosófico e artístico contemporâneo que, nas últimas décadas, ao confrontar, de um lado, uniformidade, consenso e universalidade, e, de outro, diversidade, singularidade e particularidade, arregimentam fileiras de seguidores e 
calorosos debates nas faculdades de letras mundo afora e que assumem hoje, não sem empobrecimento e reducionismo, primazia no debate político.

Com orientação teórica oposta, "O retorno de Bartleby e a crise da interpretação alocrática" também realiza um percurso histórico da teoria e, sobretudo, dos dispositivos de leitura e produção de sentido por ela empregados, mas com ênfase na denominada "Era da teoria" (1965-1980), protagonizada justamente pelos pensadores colocados em xeque no texto anterior. O ponto de partida é o prefácio elaborado por Jonathan Culler para a reedição de seu livro Pursuit of signs (2001), duas décadas após a primeira tiragem, no qual o crítico norte-americano analisa as transformações ocorridas no campo teórico durante esse intervalo. Nessa esteira, Sérgio Bellei pretende perscrutar as alterações que deslocam a ênfase conferida à interpretação em si para as suas condições de possibilidade. Sua estratégia argumentativa vale-se da exemplificação, ao recortar como objeto de análise as leituras contemporâneas de "Bartleby", intrigante conto de Melville, nas quais se verifica que a ênfase dos intérpretes transita da identidade do escrevente, isto é, da tentativa de encontrar o "sentido secreto", a "revelação" de seu estranho comportamento, para a "fórmula" com a qual o anuncia: I prefer not to, conforme salienta Gilles Deleuze, indicando a virada. Trata-se, portanto, da passagem das interpretações "alocráticas" que entendem o texto como um todo orgânico no qual se identificaria um princípio unificador e que cada uma de suas partes contribuiria para o entendimento do todo, para as "autocráticas" cuja ênfase recai no próprio interprete - os termos empregados são de E. D. Hirsch. Exemplares da referida viravolta seriam as leituras do conto realizadas por Giorgio Agambem, posteriores, mas tributárias da era de ouro da filosofia francesa, e a partir das quais Bellei se propõe a refletir sobre as políticas de interpretação que acompanham os exercícios críticos e teóricos.

Tratando de um autor que se insere na geração que se seguiu aos teóricos dos anos 1960 e 1970, Thiago Castañon também lança mão do recurso ao mapeamento teórico para, em "Um teórico na pósmodernidade", reconstituir a trajetória intelectual de Luiz Costa Lima e sua posição na história recente da teoria literária, mostrando como a obra do intelectual brasileiro, constituída no atravessamento simultâneo com a antropologia, a psicanálise e a história, se alimenta de contribuições das diversas ciências humanas e da crítica literária para "submetê-las ao tribunal de uma crítica da razão estética, convertendo-as em peças de um "processo" que propõe a refundação da teoria como análise dos limites 
da literatura". Ao alocar seu ponto de partida nas operações miméticas fundamentais, LCL, segundo o autor, confere à teoria da literatura o empenho de refletir acerca dos processos correlatos e necessariamente imbricados de subjetivação e socialização do ser humano.

Partindo igualmente de uma visão panorâmica acerca discursos sobre a teoria literária a partir dos anos 1960, "Contratradições inventadas: crise e fantasmas da Teoria", de Pedro Kalil Auad, ao mesmo tempo, nos convida a refletir sobre as formas como uma tradição de pensamento que se inventou desde sua origem, com o formalismo russo, começa a se reformular por meio do que o autor denomina como contratradições. As contratradições se constituem como processos de tradução cultural e através delas, ao mesmo tempo em que uma crise se instala, se fortalece um sentido de tradição. Nesse sentido, a leitura escapa de um estado de pessimismo infecundo para apontar como, mesmo buscando afugentar seus fantasmas, o debate teórico lida com a "possibilidade do espectro ou o espectro como possibilidade" consolidando tentativas de desobstruir a história da (crise) da teoria.

A tentativa de escapar de um estado de paralisia teórica encontrase também em "Do passado como futuro da crítica: "competência performativa" e 'formas de escrita' nos Estudos Literários", em que Nabil Araújo procede uma reflexão a respeito da posição da crítica universitária contemporânea. Partindo de um desenho em que a situação atual se deixa ver por meio da contraposição entre o monologismo da concepção de "crítica científica" de Northrop Frye e os arrombos anticríticos da "literatura como crítica de si mesma" ou da "pós-crítica", o autor busca encontrar, na interlocução com o trabalho de Ottmar Ette, um direcionamento que recupere dos textos aquilo que, para um determinado presente histórico, o nosso, seja decisivo para a invenção do futuro. Essa recuperação implica a consideração pela dimensão estéticosensorial da atividade crítica e, nessa medida, a competência performativa a que o trabalho crítico está atrelado. É nesse contexto que o diálogo entre em Ette, Auerbach e Spitzer surge para fazer pensar em formas e dispositivos que, lidos em função da tarefa de pôr em questão o papel de uma tradição disciplinar, permitem vislumbrar um jogo-como-método, necessariamente agonístico, como horizonte para a crítica. 
Também com o intento cartográfico, de mapeamento teórico, o artigo de Ronald Castellanos, "El ensayo y la crítica literaria en Cuba: el malestarde la cultura y una luz al final del túnel", traça um quadro do estado disfuncional do ensaio e da crítica literária em Cuba na contemporaneidade, trazendo novos dados para o panorama teórico vislumbrado neste número da Aletria. Diante de um cenário cultural caracterizado pela dispersão de obras e autores, pela dependência do apoio estatal para as publicações científicas e pela hegemonia das correntes críticas marxistas, bem como de práticas conservadoras e dogmáticas, derivadas de posturas pouco afeitas e exercitadas na polêmica, típicas do intelectual orgânico, o pesquisador destaca a presença e atuação do Centro Cultural Critérios, fundado pelo crítico de arte e literatura Desiderio Navarro Pérez, em 1972. Com o apoio de Salvador Redonet Cook, Navarro, por meio do Critérios e de seu periódico homônimo, desempenhou heroico trabalho de desenvolvimento e atualização teórica, por meio da realização de eventos, conferências, traduções, publicações, em suma, promovendo acesso democrático da informação cultural, com destaque recente para os cultural studies e o instrumental teórico pós-moderno, para a comunidade intelectual cubana. As condições que permeiam o trabalho crítico em Cuba trazem de ricochete, como interesse para o pesquisador brasileiro, novos e velhos problemas de ordem teórica que, ultrapassando o contexto cubano, dizem respeito a formação de uma cultura literária, a independência do trabalho intelectual, sobretudo, quando inserido em aparatos institucionais-ideológicos, assim como as sempre controversas relações do escritor e do intelectual com o Estado, que ao se configurar por meio de tensas negociações, transitam nos limiares do permissível. Nesse sentido, os mapeamentos e diagnósticos tem, em comum, a característica de serem, ao mesmo tempo, sintomas de um tempo que busca reinventar modos de existência da reflexão teórica e de exercer e conceber as atividades culturais e teórica.

Por esse viés, podemos ler "Perspectivas para uma metaforologia da antropofagia: Blumenberg, Montaigne e Oswald de Andrade" de Patrícia Lavelle. A autora revisita a antropofagia submetendo-a a novo instrumental teórico, mais especificamente à reflexão acerca da metáfora de Hans Blumenberg, autor recentemente "descoberto" por estudiosos brasileiros, sobretudo a partir da mediação e divulgação promovida com os trabalhos de Luiz Costa Lima. A triangulação entre os autores proposta inicia-se com o deslocamento de sentido que Blumenberg 
realiza, um "novo transporte", do termo visage du monde de Montaigne, com vistas a conceituar a metáfora. Daí a hipótese de que a antropofagia oswaldiana, como metáfora-teórica de uma concepção da identidade cultural fundada na alteridade, na cena do vanguardismo brasileiro, revela sua historicidade tanto em relação à noção do pensador francês quanto à do alemão. A dimensão teórica do debate formulado pela pesquisadora passa, portanto, pelas articulações, de um lado, entre metáfora e conceito, e de outro, entre metaforologia e antropologia. Todas elas contribuindo para demonstrar os modos como a metáfora se coloca ora como poesia ora como teoria, ou melhor dizendo, como ponto de cruzamento ou de não-diferenciação entre literatura e filosofia.

Enquanto Lavelle recoloca em pauta a antropofagia, metáforaconceito de Oswald de Andrade para lidar com a dependência cultural, em "Por uma crítica literária do sul global", Fernanda Dusse conduz, sob outro vértice, o debate acerca das relações de força entre culturas. Dusse parte do dilema entre autonomia e compromisso da obra de arte, entre estética e política, motivada pelo acirramento dos debates políticos e ideológicos da última década, com o intento de discutir as relações entre práticas artísticas e projetos geopolíticos contemporâneos. O texto conjuga, como referências, o recente estudo Literatura comparada e relações comunitárias (2012), de Benjamin Abdada Júnior, em que se defende a instalação de uma comunidade linguística literária como base de sustentação para a prática da Literatura Comparada, com as noções de “entre-lugar" (1969) e "cosmopolitismo do pobre" (2002), de Silviano Santiago, para propor um deslocamento do debate teórico dos centros metropolitanos europeus para um bloco transnacional, à margem e ao sul, ibero-afro-americano. Como se vê nas formulações do artigo de Freitas, Dusse constrói uma crítica às teorias pós-modernas, mas com o diferente intento de valorizar os saberes produzidos nos países do Sul global como contraponto à hegemonia econômica e cultural vigentes nas relações do mundo globalizado e, ao mesmo tempo, como caminho para a interação entre conhecimento artístico e acadêmico e prática política.

Estética e política também constitui o eixo do debate em "Discussões teórico-críticas sobre representação das margens em contos latino-americanos contemporâneos". Balizada na teoria estética de Vilém Flusser, segunda a qual o belo é "informação nova para uma experiência do real", capaz de "dar sentido à memória em sua totalidade", Alessandra Maia de Lemos toma como objeto de estudos 4 contos latino-americanos 
contemporâneos e assim formula seu problema: "como a literatura do tempo presente produzirá uma nova informação que provoque a observação crítica do espectador?” A fim de desenvolvê-lo, vale-se da noção de "choque do real", cunhada por Beatriz Jaguaribe para lidar com estéticas realistas que visam ao efeito catártico e à sensibilização social. O horizonte da investigação é o "novo realismo", que se faz notar na literatura e no cinema atuais, e a estratégia de leitura empregada é o comparatismo, elegendo narrativas de autoria da escritora uruguaia Laura Santullo, da argentina Mariana Enriquez, e dos brasileiros Marcelino Freire e Ferréz. O debate teórico elaborado, ao correlacionar elementos contextuais ligados à espetacularização da violência, às formas de representação literária dos excluídos e marginalizados socialmente, formas decorrentes da alienação da cultura do medo e do terror, somando ainda os elementos narrativos ligados ao ponto de vista, à catarse e às figurações da voz narrativa, reposiciona trânsitos e impasses entre política e estética na narrativa realista. O que está em pauta com "a estética do choque do real" são os modos de emancipação do indivíduo por meio da experiência estética e, claro, a potência da representação literária (realista) de captar, de dar a ver o mundo.

A questão da representação na literatura estudada sob o prisma dos novos realismos será retomada em "Estudos literários no Brasil: frestas para uma crítica da experiência", texto de Lígia Diniz cuja argumentação apresenta uma dinâmica bastante particular, em que o reencontro da velha questão da representação se dá com um frescor corajoso que se dedica a uma análise crítica da tradição dos estudos literários no Brasil em que se coloca em xeque a forma como, em boa parte das vezes, os problemas teóricos são, a um só tempo, tratados apenas em seus extremos e lançados ao escanteio. Ultrapassando a situação de diagnóstico, a autora apresenta, como saída para esse impasse, a constituição do crítico como leitor, isso é, um corpo afetado pelo texto literário. Proposta que pode certamente ser posta em conversação com o que Nabil Araújo apresenta em seu texto. Em ambos casos, a afetividade crítica e reflexiva seria capaz de romper com os limites atribuídos a "crítica universitária", uma vez que a universidade e os cursos de Letras seriam o locus por excelência de sua configuração e emergência: "para se ensinar literatura na escola, é preciso pensar a literatura, e que esse pensamento tem que se dar no interior da licenciatura em Letras, onde muitas vezes estamos também formando leitores, pelo exercício da aproximação do texto feita do compartilhamento da 
experiência literária". Para a autora, decididamente, "os departamentos de Letras, e em particular os de literatura, só têm a ganhar assumindo o papel de uma espécie de domínio geral das humanidades - em que o pensamento teórico, ao lado do criativo, é essencial."

A potência afetiva-criativa do pensamento, é sem dúvida, um dos pontos instigantes do pensamento de Georges Bataille, autor abordado em "Entre pensamento, arte e etnografia: O gume crítico da revista Documents", de Marília Rothier Cardoso. A análise tem como ponto de partida a publicação da tradução dos textos escritos por G. Bataille nos quinze números de Documents, mantida em circulação entre abril de 1929 e janeiro de 1931, por João Camillo Penna e Marcelo Jacques de Moraes e publicada pela editora Cultura e Barbárie em 2018. Desdobrando a série de pequenos e inquietantes ensaios, a autora procura vislumbrar a potência da interferência escrita batailliana no debate brasileiro atual, em que o encontro entre teoria e antropologia parece ser um caminho epistemológica e esteticamente fecundo e estimulante. Nesse sentido, o artigo sugere que a combinação entre trabalho argumentativo, pesquisa rigorosa e choque visual proposta por Bataille tenha muito a contribuir para a exploração reflexiva das narrativas ameríndias e afrodescendentes que, dessa forma, passam a condensar a função de preservação com a possibilidade de abertura de novos horizontes para a teoria literária e para pensamento sobre a cultura.

O impasse entre perceber o presente como estagnação e como potência de abertura ao novo reaparece na busca de interlocução contrastativa entre dois contemporâneos em plena atividade intelectual em "Sobre a dificuldade de nomear a produção do presente: Rancière e Laddaga e os regimes das artes", Ieda Magri busca refletir a respeito da dificuldade em se lidar teoricamente com a produção contemporânea a partir de uma divergência entre as posturas de Rancière e Laddaga. Essa divergência tem por finalidade, ao ser mantida pela autora em seu estado antinômico, isso é, sem síntese, asseverar para o presente da teoria sua condição de impossibilidade de estabilização em uma única tendência, fazendo coexistirem diferentes concepções, estratégias e usos da arte e da literatura. Ao opor as potencialidades das noções de "regime estético" (Rancière) e "regime prático" (Laddaga), o texto contribui para uma elaboração mais sofisticada do contemporâneo, definida pela autora como "a) o tempo histórico do qual fazemos parte; é um recorte, o atual, o tempo em que vivemos; b) a impossibilidade de se fazer uma 
definição precisa do presente e que leva a essa necessidade de se produzir permanentemente novas definições e rupturas que produzam dissenso no tempo aparentemente homogêneo da globalização; e c) uma nova forma de nomear e pensar o depois do moderno; substituição do termo pósmoderno e, nesse sentido, indicaria uma impossibilidade de se identificar uma tendência, escola ou movimento no campo dar artes, onde reinaria uma pluralidade de poéticas, concepções e usos da arte."

Compartilhando esse espaço do Contemporâneo e da necessidade preeminente de sua abertura ao novo e tendo como horizonte teórico uma Estética da Literatura pensada na esteira das reflexões de DidiHubermann sobre imagem e imaginário, em "Notas para um conceito de imagem literária", Roberto Nascimento e Caio Russo visam conjugar a necessidade de analisar a diferença entre sensibilidade e conceito com a tentativa de elaboração conceitual da imagem literária, pensada como um fenômeno desvinculado do regime sensorial da visibilidade. Dessa perspectiva, a imagem literária é, prioritariamente, o gesto que imprime um ritmo específico à linguagem, criando um espaço sensível próprio da escritura. Para os autores, uma imagem criadora, que desperta sensações e afecções, uma "imagem-textura" permite conceber o literário como um "corpo em movimento em que os afetos transitam, delimitando um espaço sensível virtual, em que os gestos sensíveis se inscrevem na escritura como acontecimento em devir".

Linhas de força centrais da teoria na contemporaneidade, como as pesquisas no campo de interartes e da crítica autobiográfica também são abordados neste dossiê. Em "A crítica (auto)biográfica brasileira contemporânea: configurações de um exercício" Jefferson Neves e Rachel Lima, revistam o discurso crítico atual a partir da questão do autor. $\mathrm{Na}$ esteira do trabalho de Leonor Arfuch (2010) e Diana Klinger (2006), os autores reafirmam a figura do autor que retorna como provocação e em tom de desafio, mapeando esse cenário intelectual a partir dos trabalhos de exercícios analíticos realizados por críticos como Eneida Maria de Souza (2007, 2011); Denilson Lopes $(1999,2002)$ e por Diana Klinger (2014). Já em "Heranças da escrita desde a condição feminina: notas sobre pintura e literatura", a autora faz um convite à reflexão sobre a relação entre pintura e escrita por meio de interessante abordagem da obra de J. Kristeva. No artigo, a aproximação entre texto e imagem visa expor e problematizar a forma como as marcas do masculino fundam o imaginário feminino. Chamando à cena a tensão psicanalítica entre os 
desdobramentos dos sentidos da visão e do gosto, a autora desdobra o fantasma arcaico da castração como a vida fantasmal sistematicamente rebaixada e soterrada das mulheres, mostrando o cruzamento ético e estético enraizado na discussão sobre a constituição da condição feminina.

Os exercícios de mapeamento da Teoria Literária apresentados neste dossiê não podem ser encerrados numa síntese capaz de reunir dialeticamente a diversidade e os desacordos que os constituem; no entanto, no recuo do olhar que promovem para pensar o porvir, revelam algumas imagens e conceitos interpostos, abrem zonas intersticiais de exploração e podem, considerados em conjunto, instituir modos de legibilidade para a complexa e desafiadora cena literária e cultural que a teoria toma para si.

Este número da Aletria ainda apresenta na, seção "Varia", dois ensaios. Matheus Trevizam, em "Camadas de ensinamento na poesia didática romana: Geórgicas e Cinegéticos", analisa com minúcia dois poemas didáticos da literatura latina, as Geórgicas, de Virgílio, e os Cynegetica, de Nemesiano. Por sua vez, Ravel Paz, em "Das demandas monstruosas: as espectropoéticas de Günter Grass em Passo de caranguejo e Thomas Bernhard em Extinção - Uma derrocada", reflete sobre a relação entre literatura e ética da representação, além de contribuir para a recepção das obras desses escritores. Finalmente, na seção "Resenha", destacam-se as contribuições de Marcos Scheffel e de Miguel Vieira pela atualidade dos livros analisados: o primeiro apresenta, de modo pertinente, as qualidades do livro Maquinação do mundo: Drummond e a mineração, de José Miguel Wisnik, e o segundo expõe com clareza a contemporaneidade da poesia de Paulo Henriques Britto em Nenhum mistério, ambas publicações revelantes para o campo dos estudos literários.

Aline Magalhães Pinto Roberto Said Márcia Arbex Marcos Antônio Alexandre 